\title{
Resveratrol: Antioxidant activity and induction of fetal hemoglobin in erythroid cells from normal donors and $\beta$-thalassemia patients
}

\author{
EITAN FIBACH ${ }^{1}$, EUGENIA PRUS ${ }^{1}$, NICOLETTA BIANCHI $^{2}$, CRISTINA ZUCCATO $^{2}$, \\ GIULIA BREVEGLIERI ${ }^{2}$, FRANCESCA SALVATORI ${ }^{2}$, ALESSIA FINOTTI $^{2}$, MICHELE LIPUCCI DI PAOLA ${ }^{3}$, \\ ELEONORA BROGNARA $^{2}$, ILARIA LAMPRONTI ${ }^{2}$, MONICA BORGATTI ${ }^{2}$ and ROBERTO GAMBARI ${ }^{2,4}$ \\ ${ }^{1}$ Department of Hematology, Hadassah-Hebrew University Medical Center, Jerusalem, Israel; \\ ${ }^{2}$ Laboratory for the Development of Pharmacological and Pharmacogenomic Therapy of Thalassaemia, \\ Biotechnology Centre, Ferrara; ${ }^{3}$ Department of Biology of Agricultural Plants, University of Pisa, \\ Pisa; ${ }^{4}$ BioPharmaNet, Department of Biochemistry and Molecular Biology, \\ Section of Molecular Biology, University of Ferrara, Ferrara, Italy
}

Received October 20, 2011; Accepted December 2, 2011

DOI: $10.3892 / \mathrm{ijmm} .2012 .928$

\begin{abstract}
Thalassemia and sickle-cell anemia (SCA) present a major public health problem in countries where the number of carriers and affected individuals is high. As a result of the abnormalities in hemoglobin production, cells of thalassemia and SCA patients exhibit oxidative stress, which ultimately is responsible for the chronic anemia observed. Therefore, identification of compounds exhibiting both antioxidant and hemoglobin-inducing activities is highly needed. Our results demonstrate resveratrol to be such a compound. This was shown both in the human K562 cell line, as well as in erythroid precursors derived from normal donors and $\beta$-thalassemia patients. Resveratrol was shown to exhibit antioxidant activity and to stimulate the expression of the $\gamma$-globin genes and the accumulation of fetal hemoglobin $(\mathrm{HbF})$. To the best of our knowledge, this is the first report pointing to such a double effect of resveratrol. Since this natural product is already
\end{abstract}

Correspondence to: Professor Roberto Gambari, Department of Biochemistry and Molecular Biology, Via Fossato di Mortara 74, 44121 Ferrara, Italy

E-mail: gam@unife.it

Abbreviations: GFP, green fluorescence protein; RFP, red fluorescence protein; $\mathrm{Hb}$, hemoglobin; $\mathrm{HbF}$, fetal hemoglobin; PBS, phosphate-buffered saline; HPLC, high performance liquid chromatography; HU, hydroxyurea; $\mathrm{PMN}$, polymorphonuclear leukocytes; GSH, reduced glutathione; SCA, sickle-cell anemia; RBC, red blood cells; ROS, reactive oxygen species; FACS, fluorescenceactivated cell sorter; MFI, mean fluorescence intensity

Key words: fetal hemoglobin, $\beta$-thalassemia, medicinal plants, resveratrol, red wine marketed as an antioxidant, future investigations should concentrate on demonstrating its potential to augment $\mathrm{HbF}$ production in experimental animal models (e.g., thalassemia and SCA mice) as well as in patients. We believe that the potential of clinical use of resveratrol as an antioxidant and $\mathrm{HbF}$ stimulator may offer a simple and inexpensive treatment to patients.

\section{Introduction}

Natural products, including extracts from medicinal plants, have been used for biomedical purposes (1-3), including the treatment of several human diseases, such as dyslipidemia and atherosclerosis (4), hepatitis (5), inflammatory diseases (6), osteoporosis and rheumatoid arthritis $(7,8)$, neoplastic diseases (9-11) and bacterial and virus infections $(12,13)$. However, there is scant information regarding the potential use of such products for the treatment of the $\beta$-hemoglobinopaties, $\beta$-thalassemia and sickle-cell anemia (SCA). The most complete of the reports of such compounds deal with mithramycin $(14,15)$, rapamycin (16-18) and psoralens (19-22). Resveratrol (3,5,4' -trihydroxystilbene, 'E' form) (23-26) is a natural phytoalexin present in the skin of grapes (50-100 $\mu \mathrm{g} / \mathrm{mg})$ and in red wine $(1.3-3 \mathrm{mg} / \mathrm{l})$ (24). It is a constituent of 'Darakchasava' (1.3-6 mg/l), an ayurvedic medicine from India (23).

Resveratrol, similarly to hydroxyurea (HU), was found to induce differentiation of K562 cells, to augment fetal hemoglobin $(\mathrm{HbF})$ production in K562 cells and in erythroid precursors isolated from SCA patients (27) and to inhibit the enzyme ribonucleotide reductase (25). Interestingly, resveratrol exhibited minimal toxicity toward normal hematopoietic cells (28).

Two biological activities of potential therapeutic drugs for $\beta$-hemoglobinopaties should be given special consideration: increasing $\operatorname{HbF}(22,29-31)$ and reducing oxidative stress (32-37). Increasing the cellular $\mathrm{HbF}$ by induction of 
the expression of the $\gamma$-globin genes has been suggested as a very promising therapeutic approach, including the reduction of the patients requirement for blood transfusions (29,38-40). Compounds studied for this activity include cell-cycle-specific agents, hematopoietic growth factors and short-chain fatty acids, which stimulate $\gamma$-globin synthesis by different mechanisms $(22,29)$. HU and butyrate analogues are the most studied compound (22). For example, Dixit et al (38) reported the results of treatment with HU of 37 patients with $\beta$-thalassemia intermedia. After a median follow-up of 12 months, 26 patients $(70.2 \%)$ responded: $45.9 \%$ were major responders (transfusion independence or $>20 \mathrm{~g} / 1$ increase in $\mathrm{Hb}$ ) and $24.3 \%$ were minor responders (a $50 \%$ reduction in transfusion frequency or a 10-20 g/l increase in $\mathrm{Hb})(22,29)$. The response was evident within one month of starting HU therapy in the majority of responders. In summing up the available clinical data, it appears that $\mathrm{HbF}$ inducers are beneficial for patients with $\beta$-hemoglobinopathies (22).

As for antioxidant activity, experimental and clinical evidence points to the important role played by oxidative stress in $\beta$-hemoglobinopathies. Using flow cytometry, we previously showed that RBC, as well as platelets and polymorphonuclear leukocytes (PMN) derived from such patients, are under oxidative stress (41). They contain lower levels of reduced glutathione (GSH), the major antioxidative compound, concomitant with increased levels of reactive oxygen species (ROS) compared with that of their normal counterparts. As a result, they have decreased membrane lipid peroxidation and exposed phosphatidylserine. Oxidative stress in thalassemia is caused primarily by degradation of unstable $\mathrm{Hb}$, which results in free globin chains and heme. Another contributing factor is iron overload due to increased intestinal absorption and regular blood transfusions (42).

Oxidative stress in blood cells affects their function: RBC precursors undergo apoptosis during their development in the bone marrow, resulting in ineffective erythropoiesis, a pathology well known in hemoglobinopathies as well as the myelodysplastic syndrome $(41,42)$. Circulating mature RBC become sensitive to extravascular hemolysis due to phagocytosis by macrophages in the reticulo-endothelial system, resulting in their short survival. Ineffective erythropoiesis and short RBC survival cause severe chronic anemia. In addition, as a result of chronic oxidative stress, PMN fail to generate oxidative bursts, an intracellular mechanism of bacteriolysis, leading to recurrent infections (42). The platelets tend to undergo activation, as reflected by exposure of phosphatidylserine, leading to thromboembolic complications in the patients. All these functional defects induced by oxidative stress are ameliorated by treatment with antioxidants (42).

Due to the importance of $\mathrm{HbF}$ augmentation and antioxidant effects in the therapy of $\beta$-hemoglobinopathies, the identification of compounds exhibiting both activities is of great importance $(22,29,41,42)$. In the present study, we investigated these activities using resveratrol in K562 cells and in erythroid precursors from normal donors and from $\beta$-thalassemia patients. Proteomic analyses were also performed to determine the overall effects of this molecule on protein expression. RT-PCR and HPLC were performed to determine whether resveratrol exerts both antioxidant and HbF potentiating activities.

\section{Materials and methods}

Materials and reagents. Resveratrol [3,5,4'-trihydroxystilbene, ' $E$ ' form] (see Fig. 1A for chemical structure and origin), angelicin, butyric acid, cytosine arabinoside, mithramycin and cisplatin were purchased from Sigma-Aldrich (Milwaukee, WI).

Cells and culture conditions. The human K562 cells (43) were cultured in RPMI-1640 medium (Sigma, St. Louis, MO, USA) supplemented with $10 \%$ fetal bovine serum (FBS; Analitica de Mori, Milan, Italy), $50 \mathrm{U} / \mathrm{ml}$ penicillin and $50 \mathrm{mg} / \mathrm{ml}$ streptomycin (14). Cell growth was determined according to cell number/ml, using a cell counter (Coulter Electronics, Hialeah, FL, USA) (14). Stock solutions of resveratrol $(50 \mathrm{mM})$ in methanol/DMSO $3 \%$ were stored at $-20^{\circ} \mathrm{C}$ in the dark and diluted immediately before use with methanol. For experiments, K562 cell cultures were initiated at $3 \times 10^{4} / \mathrm{ml}$ and the chemical inducers at the indicated concentrations were added. Following 3-5 days incubation without a medium change, erythroid differentiation was determined by staining the cells in a solution containing $0.2 \%$ benzidine in $0.5 \mathrm{M}$ glacial acetic acid, $10 \% \mathrm{H}_{2} \mathrm{O}_{2}$, as described $(14,18)$. Benzidine positivity indicates the presence of intracellular $\mathrm{Hb}$.

Human erythroid progenitors were cultured according to the two-phase liquid culture procedure as previously described $(15,44)$. In short, mononuclear cells were isolated from peripheral blood samples of normal donors and patients by Ficoll-Hypaque density gradient centrifugation and seeded in $\alpha$-minimal essential medium (Sigma-Aldrich) supplemented with $10 \%$ FBS, $1 \mu \mathrm{g} / \mathrm{ml}$ cyclosporin A (Sigma-Aldrich), 10\% conditioned medium from the 5637 bladder carcinoma cell line (44) and $10 \mathrm{ng} / \mathrm{ml}$ stem cell factor (PeproTech EC, Ltd., London, UK). After 7-day incubation in this phase I culture, the non-adherent cells were harvested, washed, and recultured in fresh medium composed of $\alpha$-medium, 30\% FBS, $1 \%$ de-ionized bovine serum albumin (Sigma-Aldrich), $10^{-5} \mathrm{M}$ $\beta$-mercaptoethanol, $2 \mathrm{mM}$ L-glutamine, $10^{-6} \mathrm{M}$ dexamethasone, $1 \mathrm{U} / \mathrm{ml}$ human recombinant erythropoietin (Tebu-Bio, Magenta, Italy) and $10 \mathrm{ng} / \mathrm{ml}$ stem cell factor. This part of the culture is referred to as phase II (44). Compounds were added on Day 4-5 of phase II and cells were harvested on Day 12. All cultures were incubated at $37^{\circ} \mathrm{C}$, under an atmosphere of $5 \% \mathrm{CO}_{2}$ in air, with extra humidity.

Measurements of oxidative stress parameters. Oxidative stress parameters were measured by flow cytometry as previously described (33). For the ROS assay, cells were incubated at $37^{\circ} \mathrm{C}$ for $15 \mathrm{~min}$ with $2^{\prime}-7^{\prime}$-dichlorofluorescein diacetate (DCF) (Sigma), dissolved in methanol (Bio-Lab, Jerusalem, Israel), at a final concentration of $0.4 \mathrm{mM}$. For the GSH assay, cells were washed with phosphate-buffered saline (PBS) and then spun down. The pellet was incubated for $3 \mathrm{~min}$ at room temperature with $40 \mu \mathrm{M}$ (final concentration) of mercury orange (Sigma). A $100 \mu \mathrm{M}$ stock solution of mercury orange was prepared in acetone and stored at $4^{\circ} \mathrm{C}$. For the lipid peroxidation assay cell suspensions $\left(5 \times 10^{6} / \mathrm{ml}\right)$ in PBS were incubated at $37^{\circ} \mathrm{C}$ for $1 \mathrm{~h}$ with $50 \mu \mathrm{M}$ N-(fluorescein-5-thiocarbamoyl)-1,2-dihexadecanoylsn-glycero-3-phosphoethanolamine, triethylammonium salt (fluor-DHPE) (Molecular Probes, Eugene, OR) dissolved in ethanol. 
Fetal hemoglobin quantification. The proportion of $\mathrm{HbF}$ (percentage of total $\mathrm{Hb}$ ) was determined by $\operatorname{HPLC}(17,22)$, using a Beckman Coulter instrument system Gold 126 Solvent Module-166 detector. Hbs were separated on a Syncropak CCM 103/25 column. The samples were eluted in a solvent gradient using aqueous sodium acetate-BisTris-KCN buffers. $\mathrm{Hb}$ was detected at $415 \mathrm{~nm}$. The standard controls were the purified $\mathrm{HbA}$ (Sigma-Aldrich, Milan, Italy) and $\mathrm{HbF}$ (Alpha Wassermann, Bologna, Italy).

Transfection of K562 cells with fluorescence protein genes under the $\gamma$-globin and the $\beta$-globin gene promoters. K562 cells were stably transfected with the pCCL.PGK.GFP.WPRE vector, and cloned green and red fluorescence protein (FP) genes under the control of the $\gamma$-globin and $\beta$-globin promoters, respectively (33). In this system, increases in the green and red signals are consistent with $\gamma$-globin and $\beta$-globin gene promoter driven activity, respectively. Transfected cells were seeded at $1.25 \times 10^{4}$ cells $/ \mathrm{ml}$ and treated with the appropriate concentrations of resveratrol. After five days of culture, the cells were assayed by a fluorescence inverted microscope, using filters suitable for either green and red fluorescence. Fluorescence intensity was measured by a spectrofluorometer. In experiments aimed at detecting the resveratrol-induced activity of the $\gamma$-globin gene promoter, the cells were harvested, washed and counted; equal numbers of cells were lysed with $0.1 \%$ Triton in PBS and centrifuged to remove cell debris. Finally, $100 \mu 1$ of cell lysate dispensed in OptiPlate-96 (Perkin-Elmer, Waltham, MA, USA) were analyzed with the aid of a Wallac 1420 Victor3 $^{\text {TM }}$ Multilabel Counter (Perkin-Elmer). The detection of green and red fluorescence was carried out using 485 and $590 \mathrm{~nm}$ emission filters, respectively (45).

FACS analysis. Cells were washed and suspended in PBS and analyzed by the FACScan (Becton-Dickinson, Franklin Lakes, NJ, USA) or FACSCalibur (Becton-Dickinson, Immunofluorometry Systems, Mountain View, CA, USA) flow cytometers, using the FL1-H channel to detect green fluorescence and FL2-H channel to detect red fluorescence and the CellQuest Pro ${ }^{\circledR}$ software for computations. Cells were passed at a rate of about $1,000 / \mathrm{sec}$, using saline as the sheath fluid. Gates were set on specific populations based on forward light scatter (FSC) and side light scatter (SSC). The results were expressed as mean fluorescence index (MFI). For every assay, unstained cells, both treated and untreated, were used as controls. For FACS analysis of the experiments described in Figs. 1 and 7, increased cellular DCF and mercury orange fluorescence indicated increased ROS and GSH contents, respectively, while increased fluor-DHPE fluorescence indicated decreased lipid peroxide content.

Globin mRNAs measurement. RNA was isolated and measured by reverse transcription quantitative real-time polymerase chain reaction (RT-PCR) as described (17) using gene-specific double fluorescence labeled probes in an ABI-Prism 7700 Sequence Detection System version 1.7.3 (Applied Biosystems, Monza, Italy). The following primer and probe sequences were used: $\gamma$-globin forward, 5'-TGG CAA GAA GGT GCT GAC TTC-3', reverse primer, 5'-TCA CTC AGC TGG GCA AAG G-3' and probe, 5'-FAM-TGG GAG ATG CCA TAA
AGC ACC TGG-TAMRA-3'; $\alpha$-globin forward, 5'-CAC GCG CAC AAG CTT CG-3', reverse primer, 5'-AGG GTC ACC AGC AGG CAG T-3' and probe, 5'-FAM-TGG ACC CGG TCA ACT TCA AGC TCC T-TAMRA-3'; $\beta$-globin forward, 5'-CAA GAA AGT GCT CGG TGC CT-3', reverse primer, 5'-GCA AAG GTG CCC TTG AGG T-3' and probe, 5'-FAMTAG TGA TGG CCT GGC TCA CCT GGA C-TAMRA-3'. The fluorescent reporter and the quencher were: 6-carboxyfluorescein and 6-carboxy-N,N,N',N'-tetramethylrhodamine, respectively. For real-time PCR the reference gene sequence was $18 \mathrm{~S}$; this probe was fluorescence-labeled with VIC (Applied Biosystems) $(15,17)$.

Proteomic analysis. Cytoplasmic extracts from treated or untreated K562 cells were prepared as described by Andrews and Faller (47). Approximately $300 \mu \mathrm{g}$ of each sample protein extract were treated with a ReadyPrep ${ }^{\mathrm{TM}}$ 2-D Cleanup kit (BioRad, Hercules, CA, USA) and the pellets were resuspended in $600 \mu \mathrm{l}$ rehydration buffer $(8 \mathrm{M}$ urea, $2 \%$ w/v CHAPS, $50 \mathrm{mM}$ DTT, $0.2 \% \mathrm{w} / \mathrm{v}$ Bio-Lyte $3 / 10$ ampholyte, $0.002 \%$ $\mathrm{w} / \mathrm{v}$ Bromophenol Blue) for isoelectric focusing (IEF). About $100 \mu \mathrm{g}$ of sample were used to rehydrate $7 \mathrm{~cm}$ long, $\mathrm{pH} 3-10$ immobilized linear $\mathrm{pH}$ gradient strips (ReadyStrip ${ }^{\mathrm{TM}}$ IPG Strip, Bio-Rad), allowing passive rehydration at room temperature for about $16-18 \mathrm{~h}(48)$. IEF was then performed at $20^{\circ} \mathrm{C}$, using a Protean IEF Cell (Bio-Rad). After a first step at $250 \mathrm{~V}$ for $20 \mathrm{~min}$, a gradient of $250-4,000 \mathrm{~V}$ was applied to the strips, followed by constant $4,000 \mathrm{~V}$, with focusing completed after $10,000 \mathrm{Vh}$. A last maintenance step at $500 \mathrm{~V}$ was performed. After IEF, the second dimension run was performed using a MiniProtean ${ }^{\circledR} 3$ (Bio-Rad) electrophoresis system, gel size $8.3 \times 7.3 \mathrm{~cm}, 4 \%$ acrylamide stacking gel and $12 \%$ acrylamide running gel. Equilibrated strips were inserted into the vertical slab gel and sealed with $0.5 \%$ low-melting point agarose, then SDS-PAGE was performed at $200 \mathrm{~V}$ for $50 \mathrm{~min}$ at room temperature (48). Precision Plus Protein Standard Plugs Unstained (Bio-Rad) was used as molecular weight markers. The gels were stained overnight with Bio-Safe Coomassie Stain (Bio-Rad). The control and resveratrol-treated samples were analyzed in quadruplicates. The 2D gels were scanned by a GS-800 Calibrated Densitometer (Bio-Rad), using the Quantity One (1-D analysis software) version 4.6.1 (Bio-Rad), to acquire images. Spot analysis was performed using PDQuest ${ }^{\mathrm{TM}}$ Basic (2-D analysis software), version 8.0 (Bio-Rad), creating two analysis sets from the protein patterns, each referring to a specific sample (control or resveratrol-treated cells). After normalizing the spot amounts in order to remove non-expression-related variations, the results were evaluated in terms of spot intensities. Statistical analysis allowed the identification of the spots which were constantly reproduced, as well as those which showed a 2 -fold differential intensity.

\section{Results}

Effects of resveratrol on the oxidative and differentiation status of K562 cells. Fig. 1B and C shows the effects of $1 \mathrm{~h}$ treatment with increasing concentrations of resveratrol (25-100 $\mu \mathrm{M})$ on ROS, GSH and lipid peroxidation in $\mathrm{K} 562$ cells. A dose-response inhibition of spontaneous and $\mathrm{H}_{2} \mathrm{O}_{2}-$ induced levels of ROS is clearly detectable (Fig. 1B). It is 

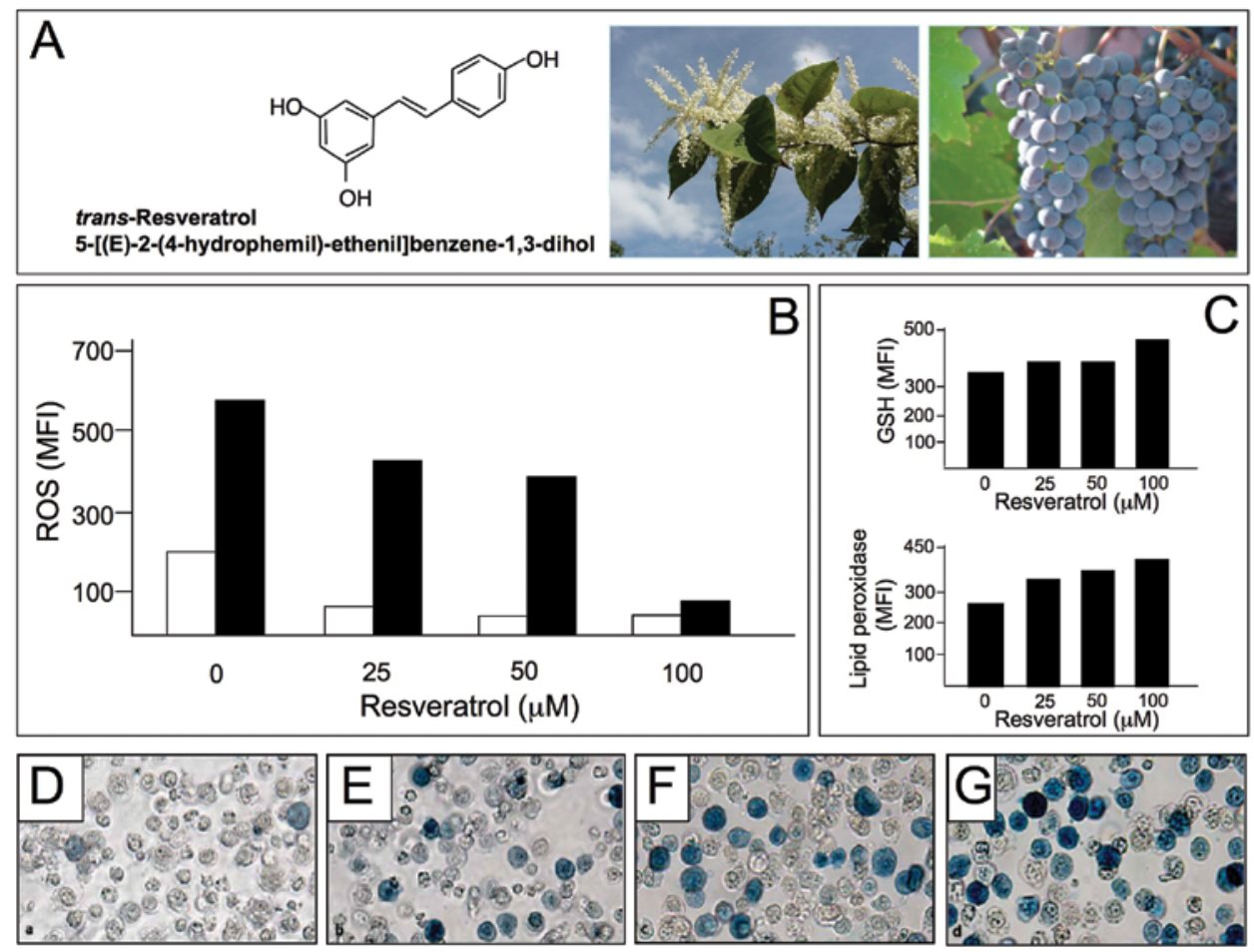

Figure 1. (A) Structure of resveratrol (left) and its natural sources (Japanese knotweed, Polygonum cuspidatum) (middle) and red grape skins (right). (B and C) K562 cells were treated with the indicated concentrations of resveratrol. After $1 \mathrm{~h}$, the cells were assayed for reactive oxygen species (ROS) in the absence (open boxes) or in the presence (black boxes) of hydrogen peroxide (B), reduced glutathione (GSH) (C, upper part of the panel) and lipid peroxides (C, lower part of the panel). (D-G) Representative benzidine assays of untreated K562 cells (D), and cells treated for 3 days with 25 (E), 50 (F) and $100 \mu \mathrm{M}$ (G) resveratrol. Benzidine positivity indicates intracellular $\mathrm{Hb}$ accumulation.
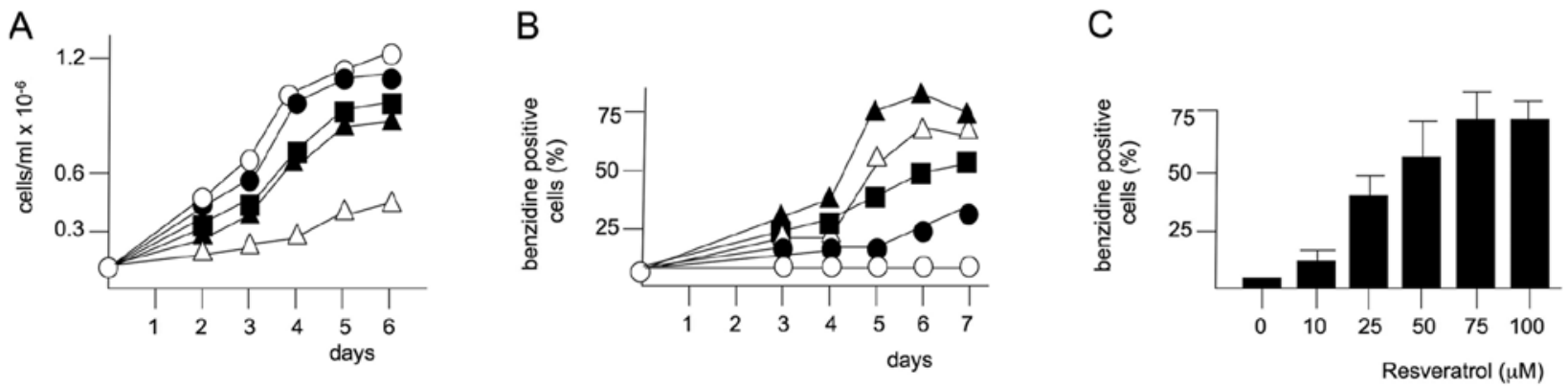

Figure 2. Effects of resveratrol on K562 cell growth and differentiation. Cells were cultured for the indicated length of time, in the absence (O) or in presence of $12.5(\bullet), 25(\bullet), 50(\Delta)$ or $100 \mu \mathrm{M}(\triangle)$ resveratrol. (A) Cell number/ml and (B) percentage of benzidine-positive cells were determined. Representative experiments are shown in (A and B). (C) K562 cells were cultured for 7 days in the absence or in the presence of the indicated concentrations of resveratrol, and the percentage of benzidine-positive cells determined. Results represent the mean \pm SD of four independent experiments.

associated with a statistically significant increase in GSH and a decrease in lipid peroxidase activity (Fig. 1C). These data strongly suggest the antioxidant activity of resveratrol. The representative data shown in Fig. 1D-G demonstrate that treatment with resveratrol was associated with an increase in benzidine-positive (Hb-containing) K562 cells.

The experiments depicted in Fig. 2 demonstrate a correlation between the effects of resveratrol on cell growth (Fig. 2A) and erythroid differentiation (Fig. 2B and C). The results obtained demonstrated that resveratrol inhibited K562 cell growth (Fig. 2A) and induced differentiation (Fig. 2B and C) in a dose-dependent fashion; growth inhibition was particularly evident at $100 \mu \mathrm{M}$, which is the most effective concentration in differentiation induction. However, it should be pointed out that resveratrol induces erythroid differentiation also at 25-50 $\mu \mathrm{M}$ (Fig. 2B and C), concentrations which do not cause major antiproliferative effects (Fig. 2A). Table I shows that induction of erythroid differentiation in K 562 cells by resveratrol is comparable to that of other inducers, including HU and butyrate, drugs which are currently in clinical use for $\beta$-hemoglobinopathies $(22,29)$.

Effect of resveratrol on $K 562$ cell protein production. In order to determine whether resveratrol induces a major perturbation of protein synthesis, K562 cells were cultured in the presence or absence of $200 \mu \mathrm{M}$ resveratrol for 4 days, then, cellular 

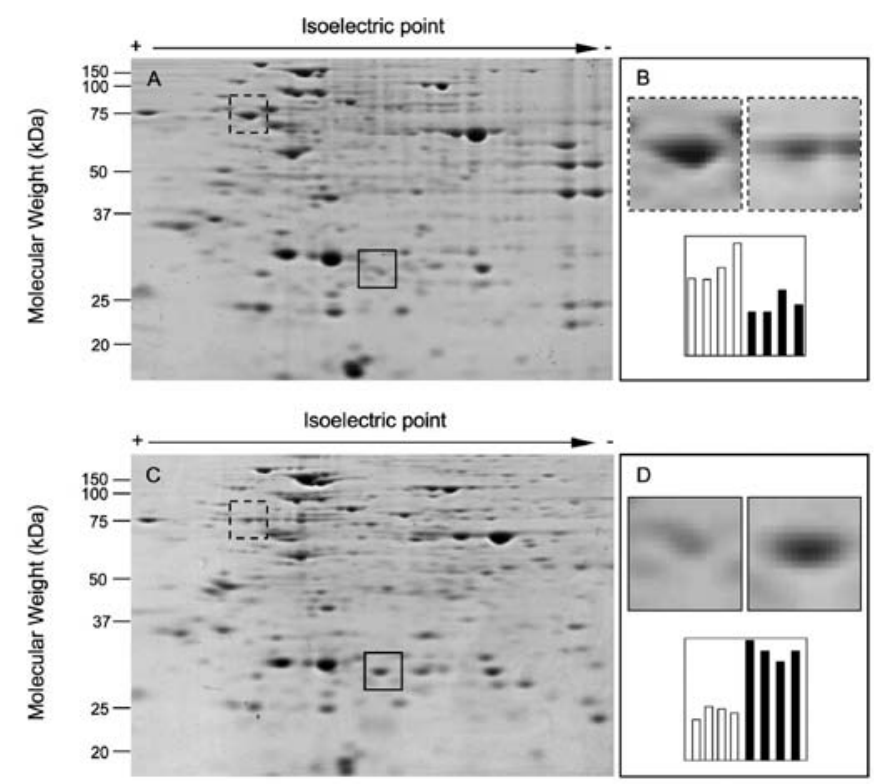

Figure 3. (A) Proteomic analysis of untreated and (C) resveratrol-treated $(200 \mu \mathrm{M}) \mathrm{K} 562$ cells. (B and D) Examples of (B) a down-modulated spot and (D) an up-modulated spot in untreated (left) relative to resveratrol-treated (right) cells. The quantitative data of these spots in untreated (open boxes) and resveratrol-treated (back boxes) in three independent proteomic analyses are shown at the bottom of panels (B and D). Details of analysis and quantification are described in Materials and methods.

proteins were extracted and analyzed by bi-dimensional gel electrophoresis. This high concentration of resveratrol was chosen because we wanted to determine possible effects on protein productions at concentrations of the inducer exceeding those found to exert antioxidative activity and $\mathrm{HbF}$ induction properties. Out of more than 200 detected protein spots only 7 displayed more than 2-fold changes (3 were upregulated, 4 were downregulated) (Fig. 3). In the experimental conditions employed, the globins migrate outside the gel. Therefore, despite the fact that further analyses are required i) to identify the proteins whose expression is altered by resveratrol and ii) to rule out effects on low-copy number cellular mRNAs, we conclude that, at the concentration used, except for its effect on the globin genes, resveratrol does not change the proteomic profile of K562 cells.

Effects of resveratrol on the transcriptional activity of the $\gamma$-globin and the $\beta$-globin gene promoters of K562 cells. To determine the effects of resveratrol on the transcription of the globin genes, we used a clonal K562 cell population stably transfected with an EGFP construct, carrying the genes for the green (EGFP) and red (RFP) FP genes, under the control of the $\gamma$-globin and the $\beta$-globin promoters, respectively (45). The cells were cultured for 5 days in the absence or presence of 25,50 and $100 \mu \mathrm{M}$ resveratrol. Representative micrographs of untreated and resveratrol-treated K562 cells are shown in Fig. 4. A concentration-dependent increase in the proportion as well as the fluorescence intensity of green-EGFP positive cells was observed.

To compare the relative effect of resveratrol on the transcriptional activity of $\gamma$-globin and $\beta$-globin promoters, the experiment depicted in Fig. 5 was performed. Cells
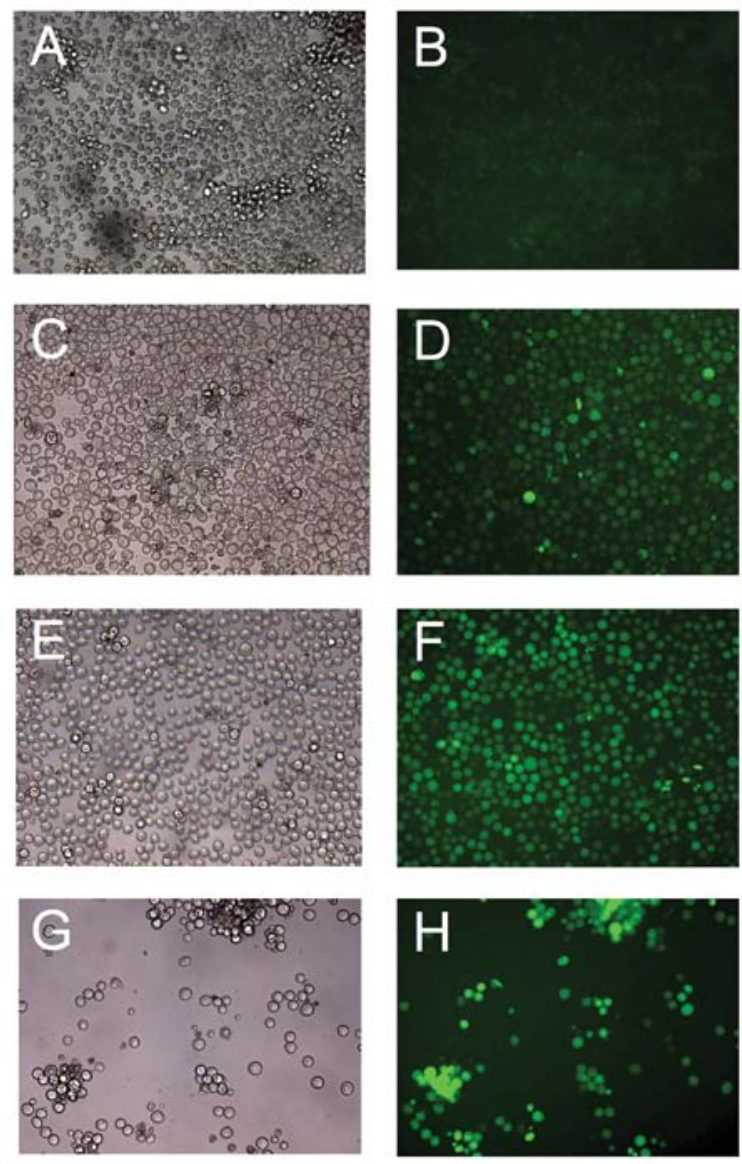

Figure 4. The effect of resveratrol on the transcriptional activity of the $\gamma$-globin gene promoter. K562 cells stably transfected with an EGFP construct were cultured for 5 days in the absence (A and B) or presence of (C and D) $25 \mu \mathrm{M}$, (E and F) $50 \mu \mathrm{M}$ and $(\mathrm{G}$ and $\mathrm{H}) 100 \mu \mathrm{M}$ resveratrol. The cells were then analyzed by phase-contrast (A, C, E and G) and fluorescence (B, D, F and H) inverted microscopes. The results show resveratrol dose-dependent increase in green fluorescence (i.e., $\gamma$-globin gene promoter activity).

Table I. Induction of erythroid differentiation in K562 cells treated with resveratrol in comparison with known inducers.

\begin{tabular}{lc}
\hline Compound (concentration) & Benzidine-positive \\
\hline Resveratrol $(100 \mu \mathrm{M})$ & $70 \pm 8.5$ \\
Angelicin $(400 \mu \mathrm{M})$ & $62 \pm 10.5$ \\
Cytosine arabinoside $(500 \mathrm{nM})$ & $75 \pm 5.4$ \\
Mithramycin $(30 \mathrm{nM})$ & $83 \pm 5.5$ \\
Cisplatin $(2 \mu \mathrm{M})$ & $63 \pm 8.5$ \\
Butyric acid $(2 \mathrm{mM})$ & $32 \pm 6.4$ \\
Hydroxyurea $(100 \mu \mathrm{M})$ & $30 \pm 7.5$
\end{tabular}

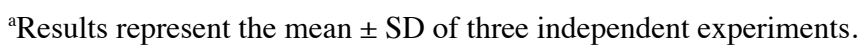

stably harbouring in their genome the pCCL.PGK.GFP. WPRE vector were treated with $100 \mu \mathrm{M}$ resveratrol, harvested after 5 days and analyzed by FACS, as described elsewhere (45). Comparing the ratio of the fluorescence of untreated vs. treated cells showed that resveratrol enhanced EGFP by $5.91 \pm 1.49$ fold, whereas the increase in RFP was 


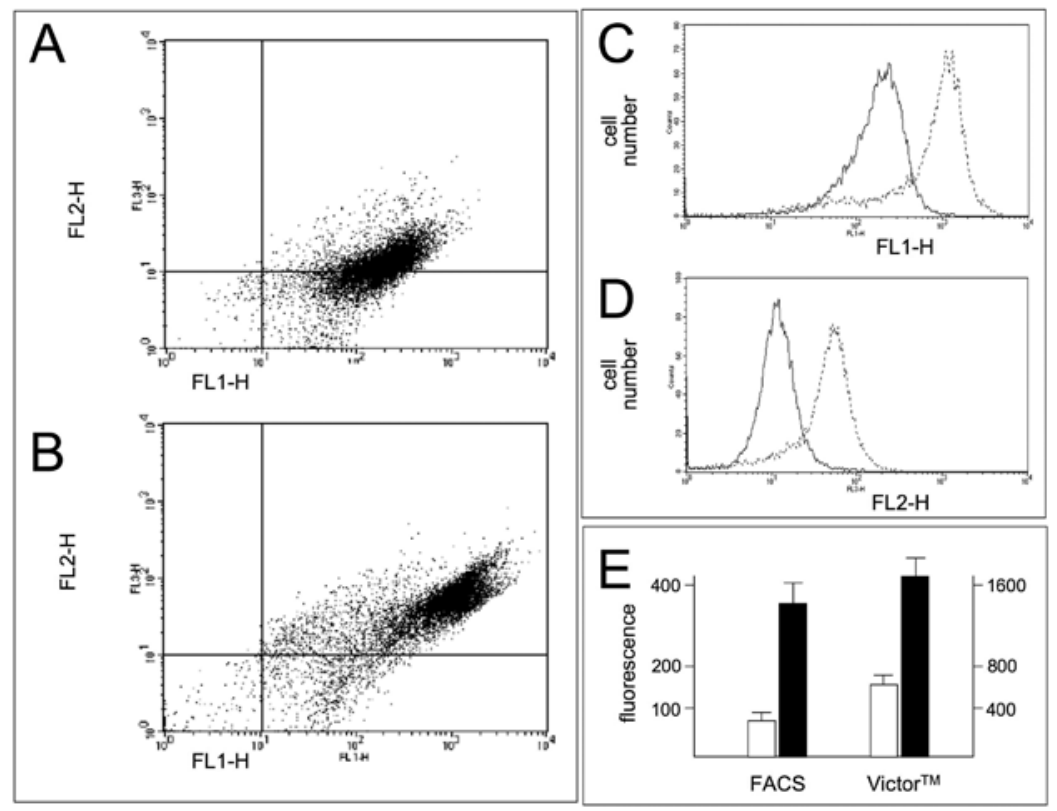

Figure 5. The effects of resveratrol on the transcriptional activity of the $\gamma$-globin and the $\beta$-globin gene promoters. K562 cells were stably transfected with the cloned green and red fluorescence protein (FP) genes under the control of the $\gamma$-globin and $\beta$-globin promoters, respectively. (A-C) FACS analysis of green fluorescence (FL1-H) and (A, B and D) and red fluorescence (FL2-H) of K562 cells stably transfected with the green FP (EGFP). (C and D) Overlay histograms of untreated cells (solid line) or cells treated for 5 days with $100 \mu \mathrm{M}$ (dotted line) resveratrol with respect to (C) FL1-H and (D) FL2-H. (E) The fluorescence of untreated cells (open boxes) and resveratrol-treated cells (black boxes) as measured by flow cytometry (FACS) (45) and spectrofluorometry (Victor ${ }^{\mathrm{TM}}$ ) (46).

Table II. Effects of resveratrol on $\mathrm{HbF}$ in erythroid precursor cells from $\beta$-thalassemia patients.

\begin{tabular}{llccc}
\hline & & \multicolumn{2}{c}{ HbF $(\%)$} & \\
\cline { 3 - 4 } Patient no. & \multicolumn{1}{c}{ Genotype } & $(-)$ & $40 \mu$ M resveratrol & HbF (fold-induction) \\
\hline 1 & $\beta^{\circ} 39 / \beta^{+}$IVS1-110 & 14.21 & 20.27 & 1.44 \\
2 & $\beta^{\circ} 39 / \beta^{\circ} 39$ & 8.08 & 18.02 & 2.24 \\
3 & $\beta^{\circ} 39 / \beta^{+}$IVS1-6 & 13.07 & 19.31 & 1.47 \\
4 & $\beta^{\circ} 39 / \beta^{+}$IVS1-110 & 10.25 & 39.27 & 3.83 \\
5 & $\beta^{\circ} 39 / \beta^{+}$IVS1-6 & 21.15 & 27.01 & 5.78 \\
6 & $\beta^{+} I V S 1-6 / \beta^{+I V S 1-110}$ & 1.97 & 11.42 & 1.75 \\
$7^{\text {a }}$ & $\beta^{\circ} 39 / \beta^{+}$IVS $1-110$ & 3.35 & 5.85 & 2.59 \\
$7^{\text {a }}$ & $\beta^{\circ} 39 / \beta^{+}$IVS1-110 & 3.5 & 9.07 & 2.11
\end{tabular}

${ }^{a}$ The results concerning the erythroid precursors from patient 7 were from peripheral blood obtained on three separate occasions.

$2.87 \pm 0.64$ fold, indicating a preferential effect of resveratrol on the $\gamma$-globin gene promoter. The quantitative effects of resveratrol were further analysed spectrofluorometrically,

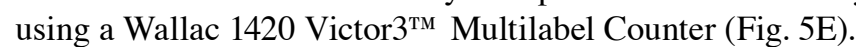

These results prompted us to determine whether resveratrol affects the oxidative stress and enhances the expression of $\gamma$-globin genes in erythroid precursors from normal human donors and $\beta$-thalassemia patients growing in culture $(15,44)$.

Antioxidant activity of resveratrol on erythroid cells from $\beta$-thalassemia patients. The effects of resveratrol on ROS and GSH of RBCs, platelets and PMNs from three $\beta$-thalassemia patients are depicted in Fig. 6. The results indicated a dose- dependent decrease in ROS, concomitant with an increase in $\mathrm{GSH}$, in all the cells studied.

The effects of resveratrol on oxidative stress markers were then studied in cultures of erythroid precursors (Fig. 7). As published previously $(41,42)$, the levels of ROS found in the erythroid precursor cells from these patients were higher than those of control cells isolated from unaffected subjects (data not shown). Resveratrol at $25-100 \mu \mathrm{M}$ was added to the cultures on Day 4 of phase II and the cells were harvested and analyzed on Day 12. The results show that resveratrol reduced the oxidative status; it inhibited both spontaneous and $\mathrm{H}_{2} \mathrm{O}_{2}-$ induced levels of ROS (Fig. 7A), increased the content of GSH (Fig. 7B) and reduced lipid peroxides (Fig. 7C). 


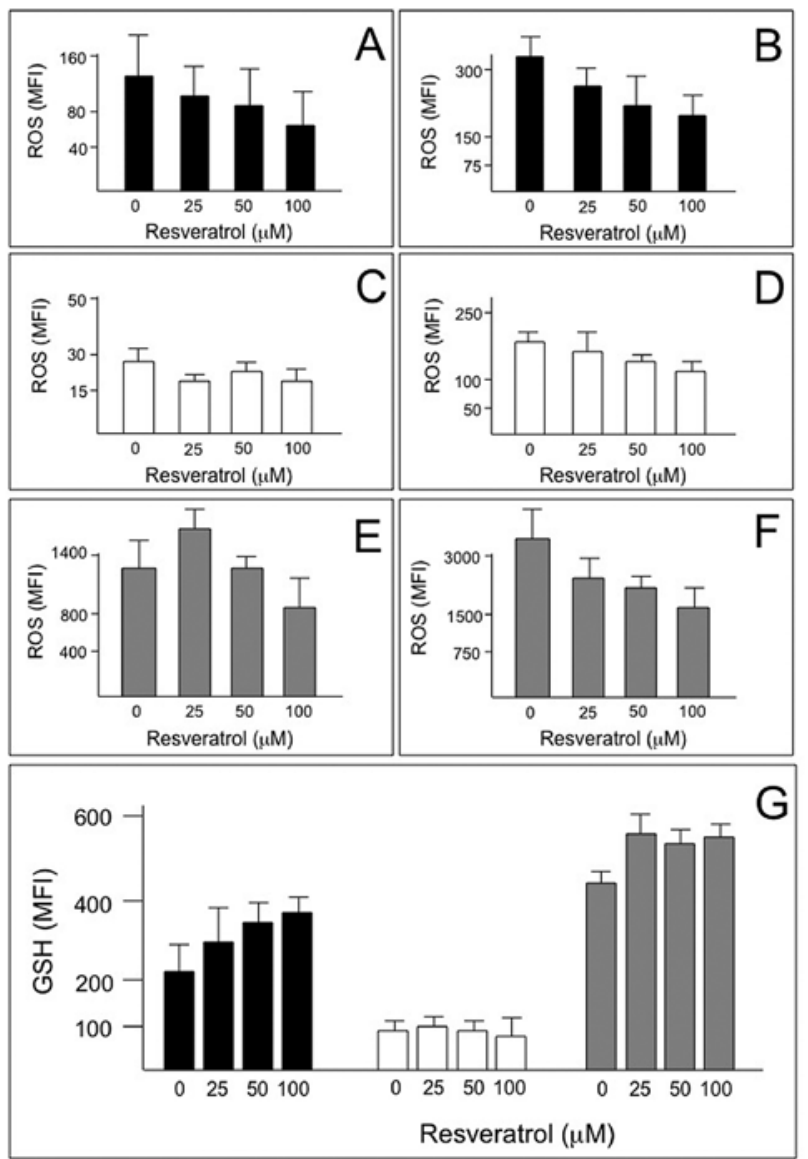

Figure 6. Effects of resveratrol on ROS of (A and B) RBC, (C and D) platelets and $(\mathrm{E}$ and $\mathrm{F}) \mathrm{PMNs}$ from three $\beta$-thalassemia patients. (A, C and $\mathrm{E}$ ) Spontaneous and (B, D and F) $\mathrm{H}_{2} \mathrm{O}_{2}$-induced levels of ROS were determined. (G) Effect of resveratrol on reduced glutathione (GSH) levels of thalassemia patient RBC (black boxes), platelets (white boxes) and PMNs (grey boxes). Cells were treated with $100 \mu \mathrm{M}$ resveratrol for $1 \mathrm{~h}$ before the assay. The mean results of three patients $\pm \mathrm{SD}$ are expressed as the mean fluorescence index (MFI).

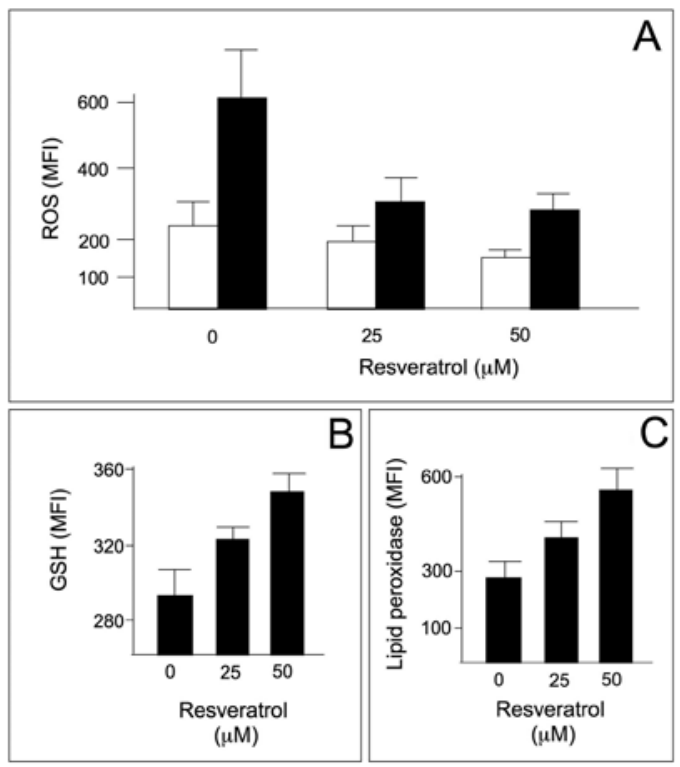

Figure 7. (A) Effects of resveratrol on ROS generation, (B) reduced glutathione (GSH) levels and (C) lipid peroxidase activity of cultured normal human erythroid cells. (A) Spontaneous (white boxes) and $\mathrm{H}_{2} \mathrm{O}_{2}$-induced (black boxes) levels of ROS were determined. The mean results of four donors \pm SD are expressed as the mean fluorescence index (MFI).

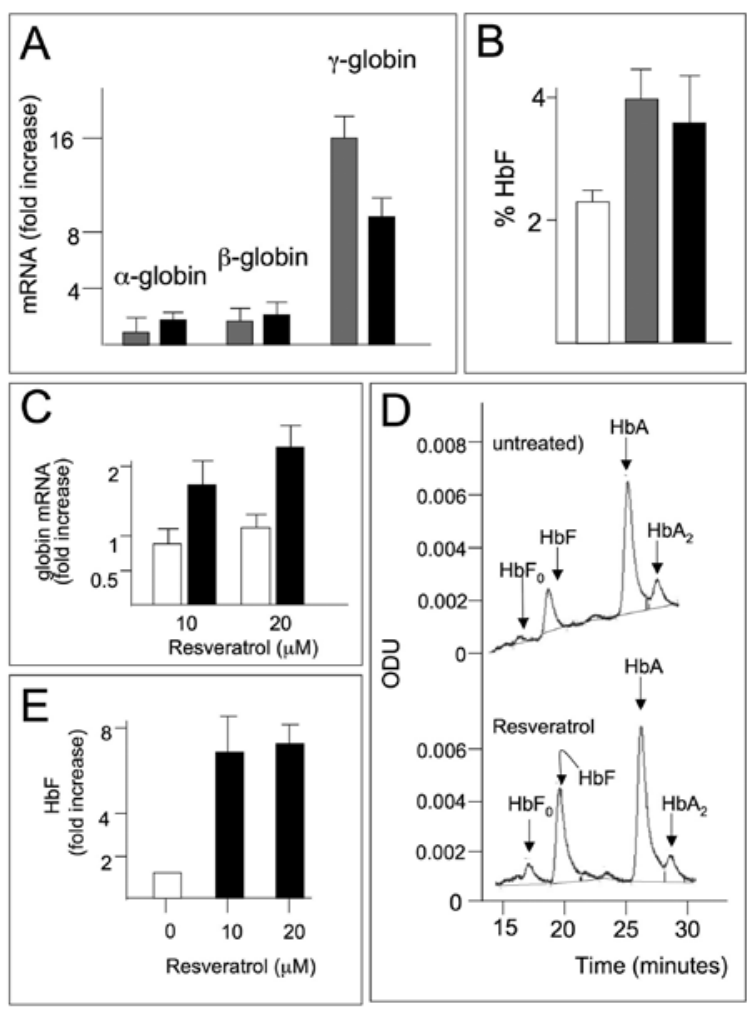

Figure 8. The effects of resveratrol on $\gamma$-globin mRNA and $\mathrm{HbF}$ in normal and thalassemia erythroid precursors. (A and B) Erythroid precursors derived from the peripheral blood of normal donors or (C-E) thalassemia patients were cultured according to the two-phase liquid procedure (17). During phase II the cells were grown with erythropoietin without (white boxes) or with the indicated concentrations of $\mathrm{HbF}$ inducers. (A and $\mathrm{C}$ ) Effects on $\gamma$-globin mRNA accumulation (fold increase with respect to control untreated cells) in (A) normal and (B) $\beta$-thalassemia cultures. (B, D and $\mathrm{E}$ ) Effects on $\mathrm{HbF}$ production in (B) normal and (D and E) thalassemia cultures. (A and B) Resveratrol (black boxes) was used at $20 \mu \mathrm{M}$ and the $\mathrm{HbF}$ inducer mithramycin (grey boxes, $100 \mathrm{nM}$ ) was used as a positive control. The results represent the mean \pm SD of 7 patients and 7 normal donors. (D) Representative HPLC analyses of lysates from control cultures (upper part of panel) and resveratrol-treated cultures (100 $\mu \mathrm{M}$, lower part of panel) from a $\beta$-thalassemia patient are shown. The results indicate increased $\gamma$-globin mRNA and $\mathrm{HbF}$ contents in resveratrol-treated cells.

Resveratrol-mediated accumulation of $\gamma$-globin mRNA and $\mathrm{HbF}$ in normal and in $\beta$-thalassemia erythroid precursors. Resveratrol $(100 \mu \mathrm{M})$ was added on Day 4-5 of phase II of erythroid cultures derived from normal donors and $\beta$-thalassemia patients. Mithramycin, a well-known potent $\mathrm{HbF}$ inducer (15) served in these experiments as a positive control. RNA was extracted and analyzed by RT-PCR. Fig. 8 shows a clear increase in $\gamma$-globin mRNA in both normal (Fig. 8A) and thalassemia (Fig. 8C) resveratrol-treated cells. An increase in $\beta$-globin mRNA was also observed, albeit at a lower level than $\gamma$-globin mRNA. Interestingly, no increase in $\alpha$-globin mRNA was detectable.

The cellular $\mathrm{Hb}$ content was analyzed by HPLC. The results (Fig. 8B) showed that the $0.55 \pm 0.6 \%$ of $\mathrm{HbF}$ in the control cultures was increased to $3.81 \pm 0.54 \%$ in resveratroltreated cultures (mean $\pm \mathrm{SD}, \mathrm{N}=4$ ). Because of the highly variable starting $\mathrm{HbF}$ levels in cells of thalassemia patients, the effects of resveratrol on $\mathrm{HbF}$ were presented as fold induction in respect to control cells (Fig. 8D and E). A representative 
HPLC analysis is shown in Fig. 8D and a summary of the results obtained in 7 thalassemia cultures is depicted Fig. 8E. Resveratrol increased $\mathrm{HbF}$ significantly and reproducibly in cultures of all the patients studied (Table II). This point is further demonstrated in Table II, which reports the effects of treatment with resveratrol in cultures derived from seven $\beta$-thalassemia patients carrying different genotypes, including one homozygous, $\beta^{\circ} 39 / \beta^{\circ} 39$, four $\beta^{\circ} 39 / \beta^{+}$IVS-110 and two $\beta^{\circ} 39 / \beta^{+}$IVS-1- 6 double heterozygous patients.

\section{Discussion}

Thalassemia and SCA present a major health problem in countries where the number of carriers and affected individuals is high (22). This assumes major importance especially in developing countries that are unable to sustain the high-cost of prevention (prenatal diagnosis) and treatment (iron-chelation and frequent blood transfusion), let alone bone marrow transplantation (49). Novel therapeutic approaches, such as gene therapy $(50,51)$, although of great potential, are not yet available, while the development of new symptom-ameliorating drugs is commercially unattractive due to the large investments required.

As a result of abnormalities in $\mathrm{Hb}$ production, thalassemia and SCA cells exhibit oxidative stress, which ultimately is responsible for the chronic anemia. Therefore, the finding of compounds exhibiting both anti-oxidant and $\mathrm{HbF}$ inducing activities is sorely needed. Our results demonstrate resveratrol to be such a compound. This was shown both in the human K562 cell line, as well as in erythroid precursors derived from normal donors and $\beta$-thalassemia patients. To the best of our knowledge this is the first report pointing to such a double effect of resveratrol.

Since resveratrol is already marketed as an antioxidant, future investigations should concentrate on demonstrating its potential to augment $\mathrm{HbF}$ production in experimental animal models (e.g., thalassemia and SCA mice) as well as in patients. We believe that the potential of clinical use of resveratrol as an antioxidant and $\mathrm{HbF}$ stimulator might offer a simple and inexpensive solution to patients. In this respect, while induction of $\mathrm{HbF}$ is of great interest, in vivo treatment of thalassemia patients has been restricted to a low number of drugs. While several reports are available on experimental systems, in vivo trials with $\mathrm{HbF}$ inducers are still scarce. HU is the most used $\mathrm{HbF}$ inducer in both moderate to severe forms of $\beta$-thalassaemia. More than 500 patients with $\beta$-thalassemia have been treated with HU worldwide and about $50 \%$ of them responded to the treatment, exhibiting a clear amelioration of the clinical parameters $(22,29,38-40)$. Other inducers of $\mathrm{HbF}$ synthesis, such as butyrate, 5-azacytidine and more recently, decitabine, have also been employed, however, these $\mathrm{HbF}$ inducers have shown only a modest response in the majority of $\beta$-thalassemia patients as well as some degree of toxicity (22).

In this respect, clinical tests with new $\mathrm{HbF}$ inducers are needed. It should be mentioned that some reported $\mathrm{HbF}$ inducers have been already used as drugs for other diseases. For instance, rapamycin, used as an immunosuppressant for the treatment of patients with kidney transplantation, and thalidomide, a drug known for its immunomodulating and antiangiogenic properties, have been demonstrated to induce $\gamma$-globin gene expression and to increase the proliferation of erythroid cells $(17,52)$.

In this context, resveratrol appears to be a fairly safe molecule to be tested in clinical trials with the objective of determining whether it stimulates in vivo $\mathrm{HbF}$ production and whether this feature depends on the genetic background of the patients.

\section{Acknowledgements}

R.G. has received a grant from AIRC, Fondazione Cassa di Risparmio di Padova e Rovigo, Cofin-2002, by UE ITHANET project (eInfrastructure for Thalassemia Network Research) and by Telethon (contract GGP10124). This research was also supported by BIOTIVIA and Associazione Veneta per la Lotta alla Talassemia (AVLT).

\section{References}

1. Bianchi N, Zuccato C, Lampronti I, Borgatti M and Gambari R: Fetal hemoglobin inducers from the natural world: a novel approach for identification of drugs for the treatment of $\beta$-thalassemia and sickle-cell anemia. Evid Based Complement Alternat Med 6: 141-151, 2009.

2. Heinrich M and Gibbons S: Ethnopharmacology in drug discovery: an analysis of its role and potential contribution.J Pharm Pharmacol 53: 425-432, 2001.

3. Samy RP, Pushparaj PN and Gopalakrishnakone P: A compilation of bioactive compounds from Ayurveda. Bioinformation 3: 100-110, 2008.

4. Wang HX and Ng TB: Natural products with hypoglycemic, hypotensive, hypocholesterolemic, antiatherosclerotic and antithrombotic activities. Life Sci 65: 2663-2677, 1999.

5. Luper S: A review of plants used in the treatment of liver disease: part 1. Altern Med Rev 3: 410-421, 1998.

6. Nicolis E, Lampronti I, Dechecchi MC, Borgatti M, Tamanini A, Bianchi N, Bezzerri V, Mancini I, Grazia Giri M, Rizzotti P, et al: Pyrogallol, an active compound from the medicinal plant Emblica officinalis, regulates expression of pro-inflammatory genes in bronchial epithelial cells. Int Immunopharmacol 8: 1672-1680, 2008.

7. Ahmed S, Anuntiyo J, Malemud CJ and Haqqi TM: Biological basis for the use of botanicals in osteoarthritis and rheumatoid arthritis: a review. Evid Based Complement Alternat Med 2: 301-308, 2005.

8. Penolazzi L, Lampronti I, Borgatti M, Khan MT, Zennaro M, Piva R and Gambari R: Induction of apoptosis of human primary osteoclasts treated with extracts from the medicinal plant Emblica officinalis. BMC Complement Altern Med 8: 59-65, 2008.

9. Khan MT, Lampronti I, Martello D, Bianchi N, Jabbar S, Choudhuri MS, Datta BK and Gambari R: Identification of pyrogallol as an antiproliferative compound present in extracts from the medicinal plant Emblica officinalis: Effects on in vitro cell growth of human tumor cell lines. Int J Oncol 21: 187-192, 2002.

10. Lambertini E, Piva R, Khan MT, Lampronti I, Bianchi N, Borgatti $\mathrm{M}$ and Gambari R: Effects of extracts from Bangladeshi medicinal plants on in vitro proliferation of human breast cancer cell lines and expression of estrogen receptor $\alpha$ gene. Int J Oncol 24: 419-423, 2004

11. Adams LS, Seeram NP, Hardy ML, Carpenter C and Heber D: Analysis of the interactions of botanical extract combinations against the viability of prostate cancer cell lines. Evid Based Complement Alternat Med 3: 117-124, 2006.

12. LeiteSP,VieiraJR, de Medeiros PL,LeiteRM,de Menezes Lima VL, Xavier HS and de Oliveira Lima E: Antimicrobial activity of Indigofera suffruticosa. Evid Based Complement Alternat Med 3: 261-265, 2006.

13. Khan MT, Ather A, Thompson KD and Gambari R: Extracts and molecules from medicinal plants against herpes simplex viruses. Antiviral Res 67: 107-119, 2005.

14. Bianchi N, Osti F, Rutigliano C, Corradini FG, Borsetti E, Tomassetti M, Mischiati C, Feriotto G and Gambari R: The DNA-binding drugs mithramycin and chromomycin are powerful inducers of erythroid differentiation of human K562 cells. Br J Haematol 104: 258-265, 1999. 
15. Fibach E, Bianchi N, Borgatti M, Prus E and Gambari R Mithramycin induces fetal hemoglobin production in normal and thalassemic human erythroid precursor cells. Blood 102: 1276-1281, 2003.

16. Mischiati C, Sereni A, Lampronti I, Bianchi N, Borgatti M, Prus E, Fibach E and Gambari R: Rapamycin-mediated induction of gamma-globin mRNA accumulation in human erythroid cells. $\mathrm{Br}$ J Haematol 126: 612-621, 2004.

17. Fibach E, Bianchi N, Borgatti M,Zuccato C, Finotti A, Lampronti I, Prus E, Mischiati $C$ and Gambari R: Effects of rapamycin on accumulation of $\alpha-, \beta$ - and $\gamma$-globin mRNAs in erythroid precursor cells from $\beta$-thalassaemia patients. Eur J Haematol 77: 437-441, 2006.

18. Zuccato C, Bianchi N, Borgatti M, Lampronti I, Massei F, Favre C and Gambari R: Everolimus is a potent inducer of erythroid differentiation and gamma-globin gene expression in human erythroid cells. Acta Haematol 117: 168-176, 2007.

19. Lampronti I, Bianchi N, Borgatti M, Fibach E, Prus E and Gambari R: Accumulation of gamma-globin mRNA in human erythroid cells treated with angelicin. Eur J Haematol 71: 189-195, 2003.

20. Viola G, Vedaldi D, Dall Acqua F, Fortunato E, Basso G, Bianchi N, Zuccato C, Borgatti M, Lampronti I and Gambari R: Induction of gamma-globin mRNA, erythroid differentiation and apoptosis in UVA-irradiated human erythroid cells in the presence of furocumarin derivatives. Biochem Pharmacol 75 810-825, 2008.

21. Viola G, Vedaldi D, Dall Acqua F, Lampronti I, Bianchi N, Zuccato C, Borgatti M and Gambari R: Furocoumarins photolysis products induce differentiation of human erythroid cells. J Photochem Photobiol B 92: 24-28, 2008.

22. Gambari R and Fibach E: Medicinal chemistry of fetal hemoglobin inducers for treatment of beta-thalassemia. Curr Med Chem 14: 199-212, 2007.

23. Paul B, Masih I, Deopujari J and Charpentier C: Occurrence of resveratrol and pterostilbene in age-old darakchasava, an ayurvedic medicine from India. J Ethnopharmacol 68: 71-76, 1999.

24. Jeandet P, Bessis R and Gautheron B: The production of resveratrol $(3,5,4$ '-trihydroxystilbene) by grape berries in different developmental stages. Am J Enol Vitic 42: 41-46, 1991.

25. Fontecave M, Lepoivre M, Elleingand E, Gerez C and Guittet O: Resveratrol, a remarkable inhibitor of ribonucleotide reductase. FEBS Lett 421: 277-279, 1998

26. Carbo N, Costelli P, Baccino FM, Lopez-Soriano FJ and Argiles JM: Resveratrol, a natural product present in wine, decreases tumour growth in a rat tumour model. Biochem Biophys Res Commun 254 739-743, 1999.

27. Rodrigue CM, Arous N, Bachir D, Smith-Ravin J, Romeo PH, Galacteros F and Garel MC: Resveratrol, a natural dietary phytoalexin, possesses similar properties to hydroxyurea towards erythroid differentiation. Br J Haematol 113: 500-507, 2001.

28. Clèment MV, Hirpara JL, Chawdhury SH and Pervaiz S: Chemopreventive agent resveratrol, a natural product derived from grapes, triggers CD95 signaling-dependent apoptosis in human tumor cells. Blood 92: 996-1002, 1998.

29. Testa U: Fetal hemoglobin chemical inducers for treatment of hemoglobinopathies. Ann Hematol 88: 505-528, 2009.

30. Lal A and Vichinsky E: The role of fetal hemoglobin-enhancing agents in thalassemia. Semin Hematol 41: 17-22, 2004.

31. Rodgers GP and Rachmilewitz EA: Novel treatment options in the severe beta-globin disorders. Br J Haematol 91: 263-268, 1995.

32. Rachmilewitz EA, Weizer-Stern O, Adamsky K, Amariglio N, Rechavi G, Breda L, Rivella S and Cabantchik ZI: Role of iron in inducing oxidative stress in thalassemia: can it be prevented by inhibition of absorption and by antioxidants? Ann NY Acad Sci 1054: 118-123, 2005

33. Amer J, Goldfarb A and Fibach E: Flow cytometric analysis of the oxidative status of normal and thalassemic red blood cells. Cytometry A 60: 73-80, 2004.
34. Afanas'ev IB: Superoxide and nitric oxide in pathological conditions associated with iron overload: the effects of antioxidants and chelators. Curr Med Chem 12: 2731-2739, 2005.

35. Anastassopoulou J, Anifantakis B, Anifantakis ZA, Dovas A and Theophanides T: The role of free radical reactions with haemoglobin and thalassaemia. J Inorg Biochem 79: 327-329, 2000

36. Amer J and Fibach E: Chronic oxidative stress reduces the respiratory burst response of neutrophils from beta-thalassaemia patients. Br J Haematol 129: 435-441, 2005.

37. Amer J and Fibach E: Oxidative status of platelets in normal and thalassemic blood. Thromb Haemost 92: 1052-1059, 2004.

38. Dixit A, Chatterjee TC, Mishra P, Choudhry DR, Mahapatra M, Tyagi S, Kabra M, Saxena R and Choudhry VP: Hydroxyurea in thalassemia intermedia - a promising therapy. Ann Hematol 84: 441-446, 2005

39. Karimi M, Darzi H and Yavarian M: Hematologic and clinical responses of thalassemia intermedia patients to hydroxyurea during 6 years of therapy in Iran. J Pediatr Hematol Oncol 27: 380-385, 2005

40. Watanapokasin R, Sanmund D, Winichagoon P, Muta K and Fucharoen S: Hydroxyurea responses and fetal hemoglobin induction in beta-thalassemia/HbE patients peripheral blood erythroid cell culture. Ann Hematol 85: 164-169, 2006.

41. Amer J, Ghoti H, Rachmilewitz E, Koren A, Levin C and Fibach E: Red blood cells, platelets and polymorphonuclear neutrophils of patients with sickle cell disease exhibit oxidative stress that can be ameliorated by antioxidants. Br J Haematol 132: 108-113, 2006

42. Amer J, Atlas D and Fibach E: N-acetylcysteine amide (AD4) attenuates oxidative stress in beta-thalassemia blood cells. Biochim Biophys Acta 1780: 249-255, 2008.

43. Lozzio $\mathrm{CB}$ and Lozzio BB: Human chronic myelogenous leukemia cell-line with positive Philadelphia chromosome. Blood 45: 321-334, 1975.

44. Fibach E, Kollia P, Schechter AN, Noguchi CT and Rodgers GP: Hemin-induced acceleration of hemoglobin production in immature cultured erythroid cells: preferential enhancement of fetal hemoglobin. Blood 85: 2967-2974, 1995.

45. Breveglieri G, Salvatori F, Finotti A, Bertuzzi I, Destro F, Falzoni S, Bianchi N, Borgatti M, Zuccato C, Feriotto G, Breda L, Rivella S and Gambari R: Cellular biosensors for the identification of fetal hemoglobin inducers. Minerva Biotecnologica 19: 123-132, 2007.

46. Lampronti I, Bianchi N, Zuccato C, Dall Acqua F, Vedaldi D, Viola G, Potenza R, Chiavilli F, Breveglieri G, Borgatti M, Finotti A, Feriotto G, Salvatori F and Gambari R: Increase of $\gamma$-globin mRNA content in human erythroid cells treated with angelicin analogues. Int J Haematol 90: 318-327, 2009.

47. Andrews NC and Faller DV: A rapid micropreparation technique for extraction of DNA-binding proteins from limiting numbers of mammalian cells. Nucleic Acids Res 19: 2499, 1991.

48. Salvatori F, Breveglieri G, Zuccato C, Finotti A, Bianchi N, Borgatti M,Feriotto G, Destro F, Canella A, Brognara E,Lampronti I, Breda L, Rivella S and Gambari R: Production of $\beta$-globin and adult hemoglobin following G418 treatment of erythroid precursor cells from homozygous $\beta^{\circ} 39$ thalassemia patients. Am J Hematol 84: $720-728,2009$.

49. Michlitsch JG and Walters MC: Recent advances in bone marrow transplantation in hemoglobinopathies. Curr Mol Med 8: 675-689, 2008.

50. Sadelain M, Lisowski L, Samakoglu S, Rivella S, May C and Riviere I: Progress toward the genetic treatment of the betathalassemias. Ann NY Acad Sci 1054: 78-91, 2005.

51. Bank A: On the road to gene therapy for beta-thalassemia and sickle cell anemia. Pediatr Hematol Oncol 25: 1-4, 2008.

52. Aguilar-Lopez LB, Delgado-Lamas JL, Rubio-Jurado B, Perea FJ and Ibarra B: Thalidomide therapy in a patient with thalassemia major. Blood Cells Mol Dis 41: 136-137, 2008. 